\title{
Correlation of Physical Activity with Stress, Depression and Anxiety in Female Students
}

\author{
Olivera Pilipović-Spasojević, ${ }^{1}$ Nenad Ponorac, ${ }^{2}$ Mira Spremo ${ }^{3,4}$
}

\section{Abstract}

Background/Aim: The period of beginning of studies is a stressful period of life in which students are expected to develop skills and abilities with which they will be able to take on the most important roles in all areas of social activity. Physical activity (PA) triggers and remodels mental health. The aim of the study was to determine the correlation between PA and stress, anxiety and depression in female students.

Methods: Epidemiological observational study was performed and included a representative sample of 408 healthy female students aged 19 to 22 years. Questionnaires were used and anthropometric measurement of weight and body mass index (BMI) calculation was performed. Used questionnaires were: a socio-demographic questionnaire, standardised tests: DASS-21 test (short version) for mental health assessment and International Physical Activity Questionnaire - IPAQ test (long version). Results: Mean age of female students was $20.5 \pm 0.72$ years, average height $168.65 \pm$ $6.01 \mathrm{~cm}$, body weight $63.09 \pm 9.9 \mathrm{~kg}$, and BMI $22.1 \pm 3.2$. A significant negative correlation was found between high PA and anxiety $(r=-0.160, p=0.001)$, PA and depression $(r=-0.118, p=0.01)$, while the category of stress had a low correlation with PA.

Conclusion: This research shows that a high level of PA has no effect on stress but has an effect on reducing anxiety and depression. Carefully planned physical activities can affect the emotional status of young female students.

Key words: Physical health; Mental health; Female students; Anxiety; Depression.
(1) Institute for Physical Medicine and Rehabilitation "Dr Miroslav Zotović", Banja Luka, the Republic of Srpska, Bosnia and Herzegovina.

(2) Department of Physiology, Faculty of Medicine, University of Banja Luka, Banja Luka, the Republic of Srpska, Bosnia and Herzegovina.

(3) Psychiatry Clinic, University Clinical Centre of the Republic of Srpska, Banja Luka, the Republic of Srpska, Bosnia and Herzegovina.

(4) Faculty of Medicine, University of Banja Luka, Banja Luka, the Republic of Srpska, Bosnia and Herzegovina.

Correspondence:

OLIVERA PILIPOVIĆ -

SPASOJEVIĆ

E: olivera0512@gmail.com

\section{ARTICLE INFO}

Received: 8 August 2020

Revision received: 3 November 2020 Accepted: 4 November 2020

\section{Introduction}

The beneficial effect that physical activity (PA) has on health and mortality reduction has been known for decades. ${ }^{1-5} \mathrm{PA}$, acts on the component of physical condition and health primarily, but it is also the driver and modulator of mental state. ${ }^{6}$, ${ }^{7}$ The need for PA is also the need to achieve a stable mood, emotional management, positive coping with stress, gaining control over overall behaviour, and even life. Greater self-esteem and self-confidence, better cognitive functioning, better mood, maintenance of normal sleep rhythm and stable mental health are just some of the effects of PA on human mental health. ${ }^{7}$
Students belong to a specific adolescent and youth population subgroup. During education, students prepared themselves to become an integrative and creative part of the society. ${ }^{8}$ Mental health issues are increasingly a problem that health workers on university campuses are actively addressing. The most common mental health complaints among students are anxiety and depression. ${ }^{9-11}$ Sometimes while under stress, young people overdo PA, exhausting themselves while trying to find a way out of a stressful situation. ${ }^{12}$ With such decisions and actions, they can sink deeper into stress. Positive effects of PA to maintain and improve health and beneficial effects on reducing stress can be ex-

Copyright $\odot 2020$ Pilipović-Spasojević et al. This is an open access article distributed under the Creative Commons Attribution License (CC BY), which permits unrestricted use, distribution, and reproduction in any medium, provided the original work is properly cited. This article should be cited as follows: Pilipović-Spasojević 0, Ponorac N, Spremo M. Correlation of physical activity with stress, depression and anxiety in female students. Scr Med 2020;51(4):244-51. 
pected only from moderate, regular PA. Otherwise, PA itself is becoming a major physical stress. $.^{13} \mathrm{Al}-$ though many of the effects of PA on mental health have been scientifically proven today, some segments of this relationship are still a subject of research and efforts are being made to improve the synergy of physical and mental health. ${ }^{14}$

The aim of this research was to determine the correlation between PA and stress, anxiety and depression among female students aged 19 to 22 years.

\section{Methods}

This observational study included a representative sample of 408 healthy full-time first- and second-year female students from various faculties of the University of Banja Luka, aged 19 to 22. Non-inclusion criteria were: students with musculoskeletal diseases (hereditary and acquired), traumas and deformities; acute and chronic diseases with a special diet and students who have been diagnosed or treated for a mental illness or disorder. The research was approved by the Ethics Committee of the Faculty of Medicine, University of Banja Luka (Approval Certificate No 18/4.56/18, dated 2 November 2018). To all students involved in the research, a detailed oral and written explanation of the research plan and programme was given and their written consent was obtained. In this research, the applicable regulations and adhered to the ethical principles of the Declaration of Helsinki were followed.

For the research, a short socio-demographic questionnaire was used, containing personal data on students' age, year of study, subjective assessment of current health as well as standardised tests: The Depression, Anxiety and Stress Scale - DASS-21 (short version) for mental health assessment and International Physical Activity Questionnaire - IPAQ test (long version). Anthropometric measurement of weight and BMI was performed with a measuring tape Seca-206 for children and adults and with the Omron Body Composition Monitor (BF511, Omron Healthcare, Hoofddorp, The Netherlands).

DASS- $21^{15,16}$ is one of the most well-known scales for assessing the degree of anxiety, depression and stress, consisting of 21 statements from which three subscales with 7 statements each are separated. Respondents were asked to express a degree of agreement with the statement in accordance with a 4 -point scale $(0=$ not at all, $1=$ little or sometimes, 2 = fairly or often; $3=$ mostly or almost always), expressing how often for the past week they have been experiencing the condition described in the statement.

The scores on each subscale range from 0 to 21 . The result of the sum for each subscale is multiplied by 2 and the total score is ranked: A) Stress: normal, mild, moderate, serious and extreme stress; B) Anxiety: normal, mild, moderate, serious and extreme anxiety; C) Depression: normal, mild, moderate, serious and extreme depression. Scoring and categorisation, as well as the use of the official version of the Serbian translation of the DASS-21 scale is available at http://www2. psy.unsw.edu.au/groups/dass. ${ }^{17}$

The IPAQ questionnaire (long version) assesses PA in different life domains (areas): PA in leisure time; PA household and gardening; PA at work; PA during transport. ${ }^{18}$ The IPAQ questionnaire contains questions about specific types of activities that are specifically researched in each of the domains: walking, moderate activities, intense activities, and high-intensity activities. The total score adds up time (in minutes) and frequency (in days) for all types of activities in the listed domains. The PA value was calculated and expressed in MET minutes per week (MET.min.wk ${ }^{-1}$ ). MET stands for "metabolic equivalent of a task" and expresses the ratio of caloric expenditure to activity related to resting consumption. One MET is $3.5 \mathrm{~mL} \mathrm{O}_{2} /$ $\mathrm{kg} / \mathrm{min}$ and represents the basal level of oxygen consumption, which corresponds to the level of resting metabolism and associated calory consumption. The value of severe PA was obtained by multiplying the time spent in severe PA in the last 7 days by a correction factor of 8 MET, moderate PA for one week was multiplied by a correction factor of 4 MET, and mild PA by 3.3 MET, which is calculated for each respondent individually. The total value of PA (total MET) is the sum of the values of heavy, moderate, and light PA that make up the independent sample. The official translation into Serbian and instructions for using the IPAQ test are available at http://www.ipaq.ki.se. ${ }^{19}$

The OMRON BF 511 instrument is a high-precision digital medical scale, which provides a wide range of measurements: after entering data on 
height (measured with altimeter for children and adults Seca-206), age and sex, the subject stands barefoot on a scale that measures body weight and automatically calculates BMI. BMI was calculated by dividing the mass $(\mathrm{kg})$ by the square of height (m) and divided into 6 categories: Malnutrition (below $18.5 \mathrm{~kg} / \mathrm{m}^{2}$ ); Ideal mass ( 18.5 to $24.9 \mathrm{~kg} / \mathrm{m}^{2}$ ); Overweight ( 25 to $29.9 \mathrm{~kg} / \mathrm{m}^{2}$ ); Mild obesity (30 to $34.9 \mathrm{~kg} / \mathrm{m}^{2}$ ); Severe obesity (35 to $39.9 \mathrm{~kg} / \mathrm{m}^{2}$ ); Extreme obesity (over $40 \mathrm{~kg} / \mathrm{m}^{2}$ );

By statistical data processing a descriptive analysis was performed and the results were presented as mean, standard deviation and measure of central value with minimum and maximum deviation. A Chi-square test was used to assess the association between categorical variables. To compare the pairs of all subscores, the Wilcoxon test and the Spearman correlation coefficient were used to define the correlation. Statistical significance was adopted at the probability level of $p<0.05$. The data has been processed by - Statistical Package for Social Sciences (SPSS) 21.0 for Windows software.

\section{Results}

The total number of 408 female students who participated in this study were aged mean $\pm \mathrm{SD}=$ $20.5 \pm 0.72$ years with an average height of 168.65 $\pm 6.01 \mathrm{~cm}$ and $63.09 \pm 9.9 \mathrm{~kg}$ body weight, which corresponds to the ideal value of BMI $(22 \pm 3.2$ $\mathrm{kg} / \mathrm{m}^{2}$ ). A total of $76.2 \%$ of students had these BMI values categorised as ideal, $12 \%$ were overweight, $1.96 \%$ had type I mild obesity and only $0.72 \%$ belonged to the type II obesity group. At the same time, $8.1 \%$ of students belonged to the malnourished group and none of them had a severe form of obesity. A descriptive presentation of anthropometric data is given in Table 1.

All study participants provided answers to the DASS-21 scale for self-assessment of depression, anxiety and stress and a long version of the IPAQ test to assess PA. The results of the descriptive statistics are given in Table 2.

The reliability of the Cronbach's alpha showed high values for stress 0.89 , anxiety 0.80 , and depression 0.84 . Checking the normality of the data distribution of these 3 scores using the Kolmog-
Table 1: Descriptive analysis of the sample according to anthropological characteristics

\begin{tabular}{lrrrrrrrr}
\hline & \multicolumn{2}{c}{ N } & Percent & Mean & SD & Minim & Maxim & Median \\
\hline Age & 408 & 100 & 20.50 & 0.72 & 19 & 22 & 20.00 \\
\hline High & 408 & 100 & 168.65 & 6.02 & 136.0 & 185.0 & 169.00 \\
\hline Weight & 408 & 100 & 63.09 & 10.00 & 42.6 & 106.1 & 61.45 \\
\hline BMl (total) & 408 & 100 & 22.10 & 3.21 & 16.0 & 36.0 & 21.60 \\
\hline BMl - underwt & 33 & 8 & 17.70 & 0.56 & 16.0 & 18.4 & 17.90 \\
\hline BMl - normal & 311 & 76 & 21.40 & 1.66 & 18.5 & 24.7 & 21.30 \\
\hdashline BMl - owerwt. & 53 & 12 & 26.79 & 1.43 & 25.0 & 29.8 & 26.60 \\
\hline BMl - obesity I & 8 & 1.96 & 31.36 & 1.63 & 30.1 & 34.3 & 30.55 \\
\hline BMl - obesity II & 3 & 0.72 & 35.67 & 0.58 & 35.0 & 36.0 & 36.00 \\
\hline
\end{tabular}

BMI: Underweight $=<18.5 ;$ Normal weight $=18.5-24.9$; Overweight $=25-29.9$; Obesity class $\mathrm{I}=30-34.9$, Obesity Class $\|=35-39.9$

orov-Smirnov test indicated that the normality of distribution did not exist and therefore a nonparametric Friedman test $\left(\chi^{2}=424.63\right.$ for $\mathrm{df}=2$ and $\mathrm{p}<0.001$ ) was performed. A strong statistically significant difference among the 3 subscores was found. By comparing pairs between all subscores (Wilcoxon test), a significant statistical difference of medians was registered between all 3 scores (anxiety /stress $\mathrm{z}=15.51, \mathrm{p}<0.001$; depressive / stress $\mathrm{z}=16.26, \mathrm{p}<0.01$ and depressive / anxiety $z=3.19, p<0.001)$. Based on the final score of the self-assessment of depression, anxiety, and stress, the total sample was stratified into 5 different category variables shown in Table 4 . In the tripartite DASS- 21 test, the state of severe and extreme depression was verified in $18.62 \%$ of participants, serious and extreme anxiety was verified in 23.5 $\%$ and serious and extreme stress in $10.5 \%$.

Descriptive analysis of IPAQ variables PA by domains - PA at work (Median 0), PA in transport (Median 1386), PA at home (Median 1158), and PA in sport (Median 1485) is shown in Table 2. The results of the Kolmogorov-Smirnov test $(\mathrm{p}<$ 0.001 ) show that the distributions of results in all domains of PA deviate from a normal distribution and statistical processing was performed based on median value. PA at work had the lowest values because only $9.1 \%$ of female students studied and worked in parallel. The median total PA during transport was 23.1 MET-hour/week with dominant walking activity. The median total PA during household maintenance was 19.3 MET-hours/week with a predominance of moderate activities at home and the median total PA during recreation and sports activities was 24.75 MET-hours/week, with predominant walking as recreation recorded. Descriptive analysis of summarised continuous variables by individual activities - PA walking, medium intensity PA and 
Table 2: Descriptive values of DASS-21 and IPAQ tests used

\begin{tabular}{|c|c|c|c|c|c|c|c|}
\hline & \multirow[b]{2}{*}{ MEAN } & \multirow[b]{2}{*}{ SD } & \multirow[b]{2}{*}{ MIN } & \multirow[b]{2}{*}{ MAX } & \multicolumn{3}{|c|}{ PERCENTILES } \\
\hline & & & & & $25^{\mathrm{TH}}$ & MEDIAN & $75^{\text {TH }}$ \\
\hline DASS stress & 17.22 & 8.83 & 0 & 42 & 10 & 16 & 22 \\
\hline DASS anxiety & 9.95 & 8.35 & 0 & 38 & 4 & 18 & 14 \\
\hline DASS depression & 8.89 & 8.96 & 0 & 42 & 2 & 6 & 12 \\
\hline \multicolumn{8}{|l|}{ TotalMETminweek } \\
\hline Work & 857.89 & 2468.45 & 0.00 & 18090 & 0.00 & 0.00 & 0.00 \\
\hline \multicolumn{8}{|l|}{ TotalMETminweek } \\
\hline Transp & 1668.46 & 1312.07 & 0.00 & 5598 & 660 & 1386 & 2772 \\
\hline \multicolumn{8}{|l|}{ TotalMETminweek } \\
\hline Home & 1809.20 & 2041.64 & 0.00 & 15678 & 562 & 1158 & 2376 \\
\hline \multicolumn{8}{|l|}{ TotalMETminweek } \\
\hline Sport & 2269.82 & 2373.28 & 0.00 & 15678 & 594 & 1485 & 3096 \\
\hline \multicolumn{8}{|l|}{ TotalWalking } \\
\hline METminweek & 3237.15 & 2333.14 & 0.00 & 12474 & 1386 & 2772 & 4356 \\
\hline \multicolumn{8}{|l|}{ TotalModerate } \\
\hline METminweek & 2325.68 & 2180.99 & 0.00 & 13440 & 720 & 1680 & 3360 \\
\hline \multicolumn{8}{|l|}{ TotalVigorous } \\
\hline MET minweek & 1024.90 & 2120.33 & 0.00 & 17280 & 0.00 & 0.00 & 1170 \\
\hline TotalMET PA & 6587.74 & 4792.34 & 0.00 & 25440 & 3101.6 & 5616 & 8586 \\
\hline
\end{tabular}

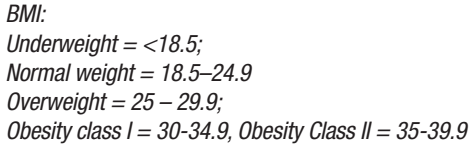

BMI:

Overweight $=25-29.9$

Obesity class I $=30-34.9$, Obesity Class $I I=35-39.9$

high-intensity PA is shown in Table 2. The median PA values during walking were 46.2 MET-hours/ week (25th percentile $=23.1$ MET-hours $/$ week, and the 75th percentile $=72.6$ MET-hours/week). The median moderate PA is 28 MET-hours/week (25th percentile $=12$ MET-hour/week, 75th percentile $=56$ MET-hour / week). Finally, the median heavy PA has the same values as the lower quartile and is 0.0 , and the mean value of the upper quartile is 19.5 MET-hours / week. Based on the cal-

Table 3: DASS 21 category variables and correlation with total IPAQ test values

\begin{tabular}{|c|c|c|c|c|c|}
\hline \multirow{2}{*}{$\begin{array}{l}\text { DASS } 21 \\
\text { test }\end{array}$} & & \multirow[b]{2}{*}{$\mathbf{N}$} & \multirow[b]{2}{*}{ Percent } & \multicolumn{2}{|c|}{$\begin{array}{l}\text { TOT MET physical } \\
\text { activity } \mathrm{min} / \text { week }\end{array}$} \\
\hline & & & & MEAN & SD \\
\hline \multirow{6}{*}{ Stress } & Normal & 178 & 43.6 & 7223.38 & 5013.84 \\
\hline & Mild & 78 & 19.1 & 6434.58 & 4970.97 \\
\hline & Moderate & 76 & 18.6 & 5820.20 & 4694.27 \\
\hline & Severe & 51 & 12.5 & 5768.12 & 4622.74 \\
\hline & Extremely & 25 & 6.1 & 6833.37 & 4611.59 \\
\hline & & 408 & 100 & & \\
\hline \multirow{6}{*}{ Anxiety } & Normal & 179 & 43.9 & 7269.27 & 4978.27 \\
\hline & Mild & 50 & 12.3 & 6845.97 & 4324.24 \\
\hline & Moderate & 83 & 20.3 & 5730.90 & 4547.56 \\
\hline & Severe & 36 & 8.8 & 6607.76 & 6002.40 \\
\hline & Extremely & 60 & 14.7 & 5632.53 & 4605.64 \\
\hline & & 408 & 100 & & \\
\hline \multirow{6}{*}{ Depression } & Normal & 266 & 65.2 & 6898.89 & 4921.39 \\
\hline & Mild & 46 & 11.3 & 5717.34 & 4375.83 \\
\hline & Moderate & 53 & 13.0 & 6994.41 & 5602.76 \\
\hline & Severe & 18 & 4.4 & 4020.58 & 3820.53 \\
\hline & Extremely & 25 & 6.1 & 6152.70 & 4005.02 \\
\hline & & 408 & 100 & 6587.70 & 5616.50 \\
\hline
\end{tabular}

culated PA level, the sample of 408 respondents were divided into $2 \%$ of women with weak, 21.8 $\%$ with moderate, and $76.2 \%$ of women with intensive activity. By final analysis, IPAQ test values (total MET mean week) for all subgroups of the triple-dependent subgroup of the DASS-21 test were calculated. Table 3 shows the percentage of distribution within the subsystems and their PA expressed in total MET (TOT MET) min/week.

The lowest value of TOT MET min/week within the subscale of all three categories DASS 21 has subgroups with severe stress $12.5 \%$ of the total sample with TOT MET min/week = 5758, extreme anxiety $-14.7 \%$ of the total sample with TOT MET min/week 5632.23) I, severe depression (4.4\% of the total sample, TOT MET min/week $=4020.58$ ) Chi-square test to assess the relationship of category variables determined the statistical significance of PA with the categories of anxiety $\left(\chi^{2}\right.$ $=11.05 ; \mathrm{p}=0.03)$ and depression $\left(\chi^{2}=10.05 ; \mathrm{p}=\right.$ 0.04), which is shown in Table 4.

Subgroups within the categories of Stress, Anxiety and Depression with TOT MET PA were compared by means of the Mann-Whitney test. Comparing the categories of Stress in relation to the TOT MET PA did not reach significance because all the girls were approximately equally active. When comparing the category Anxiety in relation to the TOT MET PA, a difference was found between group 1 (without anxiety) and Group 3 
(moderate anxiety) of the group with statistical significance of $\mathrm{p}=0.011$; Group 1 (no anxiety) and group 5 (extreme anxiety) for $\mathrm{p}=0.016$ and group 2 (mild anxiety) according to group 5 (extreme anxiety) for $p=0.049$. Comparison of the category Depression in relation to total MET PA indicated significance in the comparison of group 1 (without depression) and group 4 (severe depression) for $\mathrm{p}=0.004$, and finally group 3 (moderate depression) against group 4 (severe depression) for $\mathrm{p}=0.028$. Spearman's correlation test between DASS-21 subscores Stress, Anxiety, and Depression in relation to TOT MET PA is shown in Table 4.

Table 4: Comparison and correlation of total physical activity with the categories of stress, anxiety and depression

\begin{tabular}{lcccccc}
\hline & \multicolumn{5}{c}{ TOT MET physical activity min/week } \\
\cline { 2 - 6 } DSS 21 & \multicolumn{5}{c}{ ASYMP. } & COEF. \\
& CHI SQUARE & DF & SIG & CORELATION & P \\
\hline DASS - stress & 7.404 & 4 & 0.116 & -0.123 & 0.13 \\
\hline DASS - anxiety & 11.053 & 4 & 0.026 & -0.160 & 0.001 \\
\hline DASS - depression & 10.278 & 4 & 0.036 & -0.118 & 0.017 \\
\hline
\end{tabular}

The correlation of the tests used indicates that the increase in PA decreases the degree of stress, anxiety, and depression, recording a low degree of correlation with a high statistical significance greater than 0.001 for the category of anxiety and significant statistical significance for $p=0.01$ for the category of depression.

\section{Discussion}

Changing the environment as an epigenetic factor has an impact on the occurrence of psycho-physical diseases. Also, it affects the treatment and prevention of diseases in an individual. Thus explains that life path affects the state of health. ${ }^{20}$ The transition from high school to university education is a period of taking responsibility for oneself, one's health, and social relations. ${ }^{21,22}$ With this research, the intention was to determine the relationship between the degree of PA and stress, anxiety, and depression among female students aged 19 to 22 years. It was started with the assumption that it is a population in which no health problem is expected, from a social milieu in which moderate to intense PA through more frequent hiking is expected due to lower economic power. It was also assumed that the tests used were subjective tests of self-assessment of mental health and PA, so anthropometric measurements as a reference point for actual PA were set. A sample of 408 young women aged $20.5 \pm 0.7$ years with an ideal BMI of $22.1 \pm 3.2$ supported level of high PA that was found.

According to the results, these are people with an ideal BMI, which is a common result in the research of authors from the region. ${ }^{23-26}$ These results were different from the WHO metadata for Bosnia and Herzegovina ${ }^{27}$ where Mean BMI values of 25.1 (from 23.8 to 26.4) were recorded, which can be partly explained by the fact that the research published on the WHO page represents a heterogeneous group of females with an average age of 39.4 in relation to the target group of girls aged 19 to 22 who made up this sample.

In 1995, the DASS authors Lovibond and Lovibond developed a short version of the instrument consisting of 21 items (DASS-21), which is recommended for use in large studies. Almost all research showed that DASS scales have adequate reliability, with internal consistency that usually ranges from .80 to .95 , which is confirmed in research by Jovanović and associate ${ }^{28}$ as well as by other researchers. ${ }^{29,30,31}$ In this study, within the emotional states of depression, it was found that very often and almost always, girls could not experience any positive feeling at all (3.2\%), previous over-reactions had $21 \%$ of female students, visible disorder $16.7 \%$, difficulty to relax $33.6 \%$ and $15 \%$ of participants were is intolerant of the environment. Within the emotional states, anxiety is very often and almost always reported as dryness of mouth (5.1\%), difficulty to breathe (10.8\%), the appearance of vaults from anxiety (7.4\%), uncontrolled panic in $18.2 \%$, tachycardia due to emotion is emphasised by $17.9 \%$ and unreasonable fear is present in $15 \%$ of girls. Within the emotional states of stress, very often and almost always the lack of positive feelings has $14 \%$ of girls, difficulty to start activity $22.6 \%$, without joy $15.4 \%$, difficulty to focus $17.6 \%$, the meaninglessness of life is registered in $10.8 \%$ and as many as $36.8 \%$ of participants had a constant feeling of worthlessness. Based on the obtained results, it was determined that the subjects with mild stress $($ mean $=17.22)$ and anxiety $($ mean $=9.95)$ were without depression (mean $=8.89$ ), which differs from the research of Jovanović and associates on a sample of 1,374 students averaged 19.5 years when mean $=3.14$ for depression, mean $=3.37$ for anxiety and mean $=6.70$ for stress. ${ }^{28}$ 
Research has shown that by the age of 24, mental disorders occur in three quarters of cases. ${ }^{29}$ According to the test results, the group of moderate stress consists of 78 girls (19.1\%) while the importance of extreme stress is recorded by $18.6 \%$ of girls; $12.3 \%$ of girls belong to groups of mild anxiety, while significant and extreme feelings of anxiety were recorded in $23.55 \%$ of the girls. In the end, mild depression was found in $11.3 \%$ and significant and extreme depression in $10.5 \%$ of girls. Compared to other researchers from different backgrounds and cultural characteristics, for instance, in Egypt, the research was conducted on a sample of 442 people age $20.15 \pm 1.9$ years, it was found that BMI is above $25 \mathrm{~kg} / \mathrm{m}^{2}$. Significant and extreme stress had $36.3 \%$, anxiety of significant and extreme rank $35.6 \%$, and depression of this rank $24.4 \%$ of participants..$^{30}$ In the Iranian study by Jafari and all ${ }^{31}$ of 239 female students 7.9 $\%$ had severe and extreme-grade depression, 9.2 $\%$ anxiety and $6.3 \%$ stress. According to the WHO, there are many different mental disorders of different presentations with combinations of abnormal thoughts, perceptions, emotions, behaviours and relationships with others. The most common is depression. At the age of 19 to 22 years, which were followed by this study, based on self-assessment, expressed to extreme anxiety was found in $78(19 \%)$, which is four times more than the official WHO data and expressed extreme depression in $46(11.3 \%)$ girls, which is two times more represented than the official data for the European region, ${ }^{32}$ which may be a consequence of specific impact of the war of a country with low socio-economic status and increased migration on the territory.

PA develops functional, morphological, motor, conative and cognitive characteristics of an organism that acts systematically in the biological, health, educational, economic, recreational, and creative fields of human activities. Exercise raises the quality of life, reduces emotional distress, and enables better coping with life stressors. ${ }^{33}$ According to the recommendation of the World Health Organization, daily PA lasting at least half an hour or at least three times a week for one hour is required to improve physical or mental health. ${ }^{34}$ The PA test showed that the average values of the IPAQ test classified a small number of female students in the group of physically inactive girls (2\%), 21.8 $\%$ were moderately active, while $76.2 \%$ of female students declared themselves to be very active. Great activity can be justified to some extent by the low economic status, which forces more walking of students in everyday life. PA at work has the lowest values because according to the survey data, out of the total sample, only $9.1 \%$ of female students study and work in parallel. Walking is the most common way of migration on a daily basis and is practiced by $48.5 \%$ of girls every working day with a maximum duration of 60 minutes in $25 \%, 120$ minutes in $22.1 \%$, while $16.9 \%$ of the participants walk longer than three hours a day. Only $7.1 \%$ of participants perform strenuous physical activities during household maintenance 1 to 2 days a week for 60 minutes. Moderate activity inside the house is practiced by $41.2 \%$ of respondents 2 days a week whereas $25.5 \%$ spend 60 minutes a day on housework and $24.8 \% 120$ minutes a day. Walking as a daily recreation was recorded by $36.25 \%$ of the participants.

Only $4.9 \%$ of active athletes are engaged in training for 5 or more days during the week. In the student population, high-intensity PA has been associated with positive health effects, particularly at lower resting heart rates, higher HDL levels and slower blood glucose elevations. ${ }^{35}$ Students with retained existing levels of PA at the transition from adolescence to younger adulthood have a statistically significantly lower risk of developing cardiovascular disease and better psychological health compared to students who reduced the level of PA at that transition. ${ }^{36}$ According to the students in our research, people who exclude the presence of stress, depression and anxiety completely, are also the most physically active people. A decrease in PA is recorded with an increase in stress to a subsample categorised as extreme stress where there is a sudden jump in PA. The spiral of stress reactions is already manifested through self-assessment by changes at the psychological and fitness level. Sometimes people, while under stress, overdo PA, become exhausted trying to find a way out of a stressful situation as a form of therapy. ${ }^{37}$ However, one employing this way of "fight or flight" reaction sinks deeper into stress. Anti-stress mechanism through increased PA can affect the overall results and success of students, which can be used in some future research. Comparative descriptive analysis shows that PA values decrease with increasing degree of anxiety to the subcategory of significant anxiety, while PA in the category of depression continuously falls to the subsample of extreme depression (where a jump in PA is recorded). 
In the fight against anxiety, depression and stress, exercise helps as a way to expel negative energy from the body. By test comparison, it was found that in present sample percentage of participants whose PA is relatively high, and at the same time a high percentage of those who have high levels of stress, depression and anxiety.

This can be explained by the low degree of economic power and the location of the University faculty in different and distant parts of the city. Such statements are confirmed by the high values of activities related to walking, ie walking is the most common type of recreation. High PA scores should imply less representation of significant and extreme categories of stress, depression and anxiety, but only the anxiety category compared to PA has statistical significance with negative correlation.

\section{Conclusion}

The level of PA and behavioural changes are important indicators of the health of young female students. At the University of Banja Luka, a high level of PA was recorded. The most common form of activity is walking, while sports and recreation are not popular in this population. Unlike stress and depression, anxiety, as the most common form of behaviour change, is associated with level of PA. It is necessary to: systematically and carefully objectively monitor the health condition during studies, provide mental support to students, provide primary health prevention and promotion of sports activities through educational institutions and all forms of mass communication.

\section{References}

1. Blair SN, Kohl HW 3rd, Paffenbarger RS Jr, Clark DG, Cooper KH, Gibbons LW. Physical fitness and all-cause mortality. A prospective study of healthy men and women. JAMA 1989;262:2395-401.

2. JAMA Patient Page. The benefits of regular physical activity. JAMA 2000 Jun 14;283(22):3030.

3. Biddle SJ, Ciaccioni S, Thomas G, Vergeer I. Physical activity and mental health in children and adolescents: An updated review of reviews and an analysis of causality. Psychol Sport Exerc 2019;42:146-55.

4. Wasserman D. Physical activity improves mental health. Acta Paediatrica 2019;108(6):984-5.

5. Piercy KL, Troiano RP, Ballard RM, Carlson SA, Fulton JE, Galuska DA, et al. The physical activity guidelines for Americans. JAMA 2018;320(19):2020-8.

6. Pedersen BK. Physical activity and muscle-brain crosstalk. Nat Rev Endocrinol 2019;15(7):383-92.

7. Stubbs B, Vancampfort D, Smith L, Rosenbaum S, Schuch F, Firth J. Physical activity and mental health. Lancet Psychiatry 2018 Nov;5(11):873. doi: 10.1016/ S2215-0366(18)30343-2.

8. Višnjić A. [Models of organization of health care of stu-

\section{Conflict of interest}

None.

\section{Acknowledgements}

None.

dent population and promotion of mental health] Nis: Faculty of Medicine, University of Nis. 2010. [dissertation]. Serbian.

9. Buchanan JL. Prevention of depression in the college student population: a review of the literature. Arch Psychiatr Nurs 2012;26:21-42.

10. Auerbach RP, Mortier P, Bruffaerts R, Alonso J, Benjet C, Cuijpers P, et al. WHO World Mental Health Surveys International College Student Project: prevalence and distribution of mental disorders. J Abnorm Psychol 2018 Oct;127(7):623-38.

11. Watkins DC, Hunt JB, Eisenberg D. Increased demand for mental health services on college campuses: perspectives from administrators. Qual Soc Work 2012;11:319-37.

12. Sharkey B, Gaskill. [Exercise and health]. Beograd: Data Status; 2008.

13. Hadžikadunić A, Turković S, Tabaković M. [Sports theory with the basics of special-purpose physical activity]. Sarajevo: Faculty of Sports and Physical Education; 2013.

14. Scully D, Kremer J, Meade MM, Graham R, Dudgeon K. 
Physical exercise and psychological well being: a critical review. Br J Sports Med 1998;32:111-20.

15. Clark LA, Watson D. Tripartite model of anxiety and depression: psychometric evidence and taxonomic implications. J Abnorm Psychol 1991 Aug;100(3):316-36.

16. Lovibond PF, Lovibond SH. The structure of negative emotional states: comparison of the Depression Anxiety Stress Scales (DASS) with the Beck Depression and Anxiety Inventories. Behav Res Ther 1995;33:335-43.

17. DASS-21 in Serbian. [cited 2020 May 14]. Available from: http://www2.psy.unsw.edu.au/dass.

18. Craig C. L, Marshall A. L, Sjöström M, Bauman A. E, Booth M. L, Ainsworth B. E, et al. International physical activity questionnaire: 12-country reliability and validity. Med Sci Sports Exerc 2003;35(8):1381-95.

19. IPAQ test, translation into Serbian. [cited 2020 May 16]. Available from: http://www.ipaq.ki.se.

20. Ben-Shlomo Y, Kuh D. A life course approach to chronic disease epidemiology: conceptual models, empirical challenges, and interdisciplinary perspectives. Int J Epidemiol 2002;31(2):285-93.

21. Ćurković S. [Kinesiological activities and risky behaviors of students] [dissertation]. Zagreb: University of Zagreb, Faculty of Kinesiology; 2010. Croatian.

22. Wei CN, Harada K, Ueda K, Fukumoto K, Minamoto K, Ueda A. Assessment of health-promoting lifestyle profile in Japanese university students. Environ Health Prev Med. 2012; 17:222-7.

23. Crnobrnja V, Sredić B, Stokić E, Dujmović D, Andrejić B. [Analysis of the frequency of risky forms of obesity in students of the University of Novi Sad]. Med Pregl 2012;45:3-4.

24. Mašina T. [Relationship between anthropometric characteristics, motor abilities, healthy habits, and self-esteem among medical students] [dissertation]. Zagreb: University of Zagreb -- faculty of Medicine; 2019. Croatian.

25. Alić J. [Relationship between female students' physical activity, self-assessment of health, and satisfaction with physical appearance] [dissertation]. Zagreb: University of Zagreb - Faculty of Kinesiology; 2015. Croatian.

26. Ilić-Živojinović JB. [Analysis of the relationship between socio-environmental factors and academic stress with student mental health] [dissertation]. Belgrade: University of Belgrade - Faculty of Medicine; 2015. Serbian.
27. WHO. The global health observatory. Explore a world of health data. [cited 2020 May 4]. Available from https://www.who.int/data/gho/data/indicators/indicator-details/GHO/mean-bmi-(kg-m-)-(age-standardized-estimate).

28. Jovanović V, Gavrilov-Jerković V, Žuljević D, Brdarić D. [Psychometric evaluation of the Depression, Anxiety, and Stress Scale-21 (DASS-21) on a sample of students in Serbia]. Psihologia 2014;47(1):93-112.

29. Kessler RC, Berglund P, Demler O, Jin R, Merikangas $\mathrm{KR}$, Walters EE. Lifetime prevalence and age-of-onset distributions of DSM-IV disorders in the National Comorbidity Survey Replication. Arch Gen Psychiatry 2005;62(6):593-602.

30. Wahed WY, Hassan SK. Prevalence and associated factors of stress, anxiety, and depression among medical Fayoum University students. Alexandria J Med 2017;53(1):77-84.

31. Jafari P, Nozari F, Ahrari F, Bagheri Z. Measurement invariance of the Depression Anxiety Stress Scales-21 across medical student genders. Int J Med Educ 2017 Mar 30;8:116-22.

32. World Health Organization [WHO]. Depression and other common mental disorders: global health estimates. Geneva: World Health Organization; 2017.

33. Brundtland GH. From the World Health Organization. Reducing risks to health, promoting healthy life. JAMA 2002;288:1974.

34. WHO. A Guide for population-based approaches to increasing levels of physical activity. Geneva; 2007. [cited 2020 Apr 24]. Available from: https://www.who. int/diet physical activity/physical-activity-promotion-2007.pdf.

35. Schilter J, Dalleck L. Fitness and fatness: indicators of metabolic syndrome and cardiovascular disease risk factors in college students? J Exerc Physiol Online 2010;13(4):29-39.

36. Rangul V, Bauman A, Holmen TL, Midthjell K. Is physical activity maintenance from adolescence to young adulthood associated with reduced CVD risk factors, improved mental health, and satisfaction with life: the HUNT Study, Norway. Int J Behav Nutr Phys Act 2012 Dec 14;9(1):144. doi: 10.1186/1479-5868-9-144.

37. Sharkey BJ, Gaskill SE. Fitness \& health. 7th ed. Leeds: Human Kinetics; 2013. 